\title{
Rapid Atmospheric Leaching of Chalcopyrite Using a Novel Reagent of Trichloroisocyanuric Acid
}

\author{
Guobao Chen ${ }^{1, *(\mathbb{D}}$, Jiarui Sun ${ }^{1}$, Hongying Yang ${ }^{1}$, Pengcheng $\mathrm{Ma}^{2}$ and Shixiong Gao ${ }^{1}$ \\ 1 School of Metallurgy, Northeastern University, Shenyang 110819, China; sjr19980516@gmail.com (J.S.); \\ smile1985zll@gmail.com (H.Y.); gsx15226572109@gmail.com (S.G.) \\ 2 Shandong Zhaojin Group Co., Ltd., Zhaoyuan 265400, China; mapengcheng1805@dingtalk.com \\ * Correspondence: chengb@smm.neu.edu.cn; Tel.: +86-24-83681319
}

Citation: Chen, G.; Sun, J.; Yang, H.; Ma, P.; Gao, S. Rapid Atmospheric Leaching of Chalcopyrite Using a Novel Reagent of Trichloroisocyanuric Acid. Minerals 2021, 11, 1012. https://doi.org/ $10.3390 / \min 11091012$

Academic Editors: Weiguo Xie, Eiman Amini and Hylke J. Glass

Received: 22 August 2021

Accepted: 13 September 2021

Published: 18 September 2021

Publisher's Note: MDPI stays neutral with regard to jurisdictional claims in published maps and institutional affiliations.

Copyright: (c) 2021 by the authors. Licensee MDPI, Basel, Switzerland. This article is an open access article distributed under the terms and conditions of the Creative Commons Attribution (CC BY) license (https:/ / creativecommons.org/licenses/by/ $4.0 /)$.

\begin{abstract}
With the decrease in high-grade chalcopyrite resources, the copper extraction from lowgrade chalcopyrite has attracted more and more attention. However, the kinetic rates of chalcopyrite leaching with traditional oxidants are usually very slow due to the formation of the passivation layer. In this study, a novel reagent of chlorinated oxidant, trichloroisocyanuric acid (TCCA), was used to leach chalcopyrite for the first time. The experimental results showed that when the initial oxidant concentration for TCCA was $0.054 \mathrm{~mol} \cdot \mathrm{L}^{-1}$, the leaching temperature was kept at $55{ }^{\circ} \mathrm{C}$, and the $\mathrm{pH}$ of the pulp was controlled at 1 , the oxidation efficiency of $\mathrm{Cu}$ can reach above $90 \%$ in less than $30 \mathrm{~min}$. Various analyses of chalcopyrite mineral ore and its oxidized residues, such as chemical composition analysis, $\mathrm{X}$-ray diffraction analysis, scanning electron microscopy analysis and X-ray photoelectron spectroscopy, were conducted, respectively. No obvious passivation layer was found on the chalcopyrite surface, though the sulfur product can also be generated during the leaching. Reaction kinetic analysis results showed that the different influence of surface reaction and diffusion process on the dissolution of chalcopyrite is little due to the fast leaching speed. After calculation, the activation energy of the whole leaching reaction is $9.06 \mathrm{~kJ} \cdot \mathrm{mol}^{-1}$, much lower than that in other reports. The mechanism was also proposed that TCCA was hydrolyzed in the solution to form hypochlorous acid, which is the strong oxidant, and cyanuric acid, which prevents the formation of a passivation layer. The processing in this study is expected to be applied as a novel method for atmospheric leaching of chalcopyrite.
\end{abstract}

Keywords: chalcopyrite; atmospheric leaching; trichloroisocyanuric acid; mechanism

\section{Introduction}

Chalcopyrite is an extremely important copper-bearing mineral, which represents nearly $70 \%$ of the world's copper reserves [1]. Although more than $80 \%$ of copper is currently recovered through pyrometallurgy, due to its comparative inferiority with the continuous decline grade of copper ore and stricter environmental protection requirements, more and more technological development has been toward hydrometallurgical processes [2]. The leaching systems in the previous reports include a sulfate system [3], chlorination system [4], alkaline system [5], and nitrate system [6], etc. Several common oxidants, such as trivalent iron, copper ion, methanesulfonic acid, hydrogen peroxide, ozone, potassium dichromate, ammonium persulfate, and sodium hypochlorite, have also been researched to enhance the leaching efficiency [7-9].

Chalcopyrite is a kind of mineral that has high crystal lattice energy. Thus, its dissolution is very difficult, and the copper extraction is generally low under atmospheric pressure [1]. Moreover, a passivation layer can be easily formed on the surface of the chalcopyrite mineral during the leaching process to prevent its further dissolution, especially in the sulfate system [10]. The components of these passivation layers include elemental sulfur, polysulfide, or iron compounds [11]. Therefore, one of the research hotspots is to 
study the formation and elimination of the surface passivation layer; for example, using high-temperature and high-pressure conditions [12], ultrafine grinding of minerals [13] microwave or ultrasonic-assisted leaching $[14,15]$, adding silver ions for catalytic desulfurization, applying solvents to dissolve sulfur [2], etc. However, these methods are often limited in economic cost or industrial scale applications.

In order to dissolve the copper of chalcopyrite, the oxidant applied for leaching chalcopyrite need to have a high potential to oxidize sulfur in chalcopyrite to elemental sulfur or sulfate. Hypochlorous acid is well known as a strong oxidant for leaching sulfide minerals, and its oxidizing power even exceeds peroxide, oxygen and chlorate. Ikiz [16] found that with the optimum leaching conditions that an initial $\mathrm{pH}$ of 5 , a hypochlorous acid concentration of $0.2 \mathrm{~N}$ for a solid/liquid ratio of $4 \mathrm{~g} \cdot \mathrm{L}^{-1}$, and room temperature, copper dissolution rose quickly from $40 \%$ to $80 \%$ in $15 \mathrm{~min}$. They also found that the diffusion process through the product layer mainly influenced the leaching rate, and its activation energy is $19.88 \mathrm{~kJ} \cdot \mathrm{mol}^{-1}$. However, hypochlorous acid and hypochlorite are unstable and easily decompose, leading to high oxidant consumption and cost. Choubey [17] found a possible two-step process to selectively leach chalcopyrite, which firstly converted chalcopyrite into an alkaline solution using hypochlorite solution and then leached the oxidation residue with dilute acid. However, its efficiency is not high. Therefore, the application of novel oxidants to overcome the formation of a passivation layer during the chalcopyrite leaching process and to achieve rapid oxidative leaching is of great significance to copper extraction.

Trichloroisocyanuric acid (TCCA), chemical formula [1,3,5-trichloro-1,3,5-triazine$2,4,6-(1 \mathrm{H}, 3 \mathrm{H}, 5 \mathrm{H})$-trione], is a versatile and efficient compound for chlorination and oxidation reactions. Because of its chlorinating and oxidizing properties, it is used as a bleaching agent, disinfectant and bactericide [18]. Furthermore, it is more stable than hypochlorous acid and can provide a continuous high concentration of available chlorine in the leaching system. Furthermore, it is safe and harmless to the environment $[19,20]$. The purpose of this work aims at exploring the feasibility of applying the novel oxidant to leach chalcopyrite so as to improve the extraction of copper under relevant industrial conditions.

\section{Experimental}

\subsection{Minerals and Reagents}

The high-grade massive chalcopyrite ore applied in the leaching experiments came from a mine located in the Yunnan Province, China. The ore was crushed and ground to less than $74 \mu \mathrm{m}$. The quantitative analysis results through an inductively coupled plasmaoptical emission spectrometry (ICP-OES) (AVIO500, Perkin-Elmer, Waltham, MA, USA) instrument showed that the main elements were copper, iron and sulfur, and their mass fractions were $32.23 \%, 32.51 \%$ and $35.10 \%$, respectively. The component content is similar to that of chalcopyrite. X-ray diffraction (XRD) analysis of the phase (as shown in Figure 1) suggests that the main phase of the ore specimen is chalcopyrite. The analytical grade trichloroisocyanuric acid used as the leaching reagent was purchased from Sinopharm Chemical Reagent Co., Ltd. of Shanghai, China. Analytical grade chemicals $\mathrm{H}_{2} \mathrm{SO}_{4}$ and $\mathrm{NaOH}$, are used as the reagents for adjusting the acidity of the solution in the leaching process. Deionized water (resistivity of $18.2 \mathrm{M} \Omega \cdot \mathrm{cm}$ at $25^{\circ} \mathrm{C}$ ) was applied for preparing the solutions.

\subsection{Leaching Experiments}

For each leaching experiment, the designed amount of trichloroisocyanuric acid was firstly weighed and put into a $500 \mathrm{~mL}$ three-mouth flask, then the deionized water was added to dissolve the oxidant and form the solution with a given concentration. After adjusting the acidity, the flask was placed in a constant-temperature water bath under magnetic stirring $(200 \mathrm{rpm})$. When the temperature of the system reached a constant value, a certain amount of ground chalcopyrite powder was added into the solution for leaching 
and timing began. The solid-liquid ratio was fixed at 1g:0.2 L for all of the leaching tests. To monitor the concentration of copper and iron in the oxidizing process, extractions were made periodically with the agitation temporarily turned off, then filtered with filter paper and sampled. After the leaching experiments were completed, the remaining residues were filtered, washed, and dried for further researches at room temperature. The filtrate was cooled to room temperature, and then the copper concentration in the oxidizing solution was measured. The oxygenation efficiency (\%) of $\mathrm{Cu}$ and Fe were calculated with $\mathrm{Cu}$ and Fe contents in the oxidizing liquid, dividing the mass of copper and iron in the feeding chalcopyrite. The oxygenation efficiency (\%) of sulfur was calculated with $\mathrm{S}$ content in the leached residue dividing the mass of sulfur in the feeding chalcopyrite.

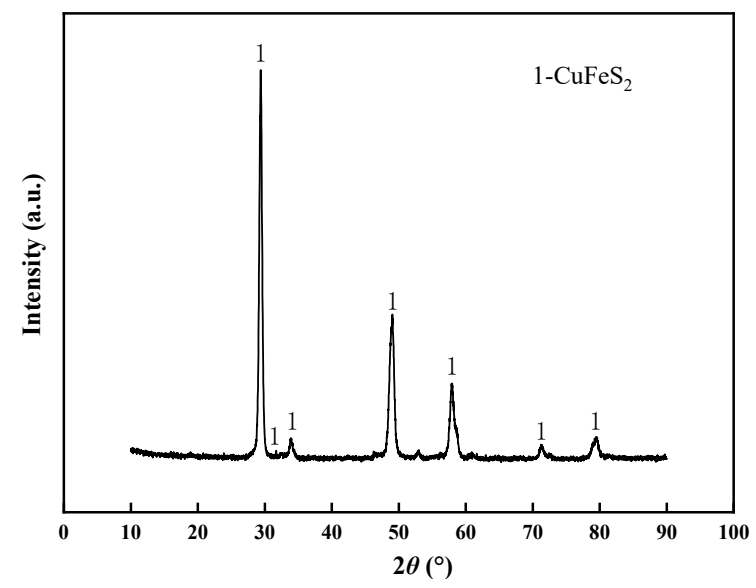

Figure 1. XRD test result of chalcopyrite sample.

\subsection{Characterization and Analysis of Samples}

The phase composition of chalcopyrite specimens and residues before and after leaching were determined using X-ray diffraction (XRD) (non-monochromatic $\mathrm{Cu}$ of K $\alpha$ X-ray source; D8 Advanced Bruker, Germany). XRD data were collected in the detection range of $10-90^{\circ}$ with a scanning speed of $0.1^{\circ} \mathrm{s}^{-1}$. Before X-ray diffraction analysis, chalcopyrite was ground and sieved to $<74 \mu \mathrm{m}$. The surface images of chalcopyrite mineral and oxidized residue were determined by a high-resolution field emission scanning electron microscope (SEM) (TESCAN MIRA3, Czech). Surface morphologies were observed, employing an accelerating voltage of $15 \mathrm{kV}$ with different magnifications. A thermo ESCALAB 250 spectrometer (Thermo Scientific, Waltham, MA, USA) was used to measure the XPS of the chalcopyrite sample. It was conducted at $15 \mathrm{kV}$ and $150 \mathrm{~W}$ in an ultra-high vacuum, with monochromatic $\mathrm{Al} \mathrm{K} \alpha$ radiation $(1486.6 \mathrm{eV})$ as an excitation source. The narrow scan energy was controlled at $50.0 \mathrm{eV}$. The adventitious $\mathrm{C}$ 1s peak was used to correct binding energies to $284.8 \mathrm{eV}$ and the acquired spectra of $\mathrm{Cu}, \mathrm{Fe}$, and $\mathrm{S}$ were fitted using CasaXPS software. Atomic absorption spectrometer (AAS) (Agilent AA240FS instrument, USA) was used to measure the copper concentration in the filtrate.

\section{Results and Discussion}

\subsection{Extraction Curves with TCCA}

The effect of reaction conditions ( $\mathrm{pH}$ value, reaction time $t$, the initial TCCA concentration $\mathrm{C}_{0}$, and the solution temperature $T$ ) on the $\mathrm{Cu}$ extraction was investigated. It was conducted under one altered condition while the other variables were kept constant. The experimental results are shown in Figure 2. $\mathrm{Cu}$ and Fe extraction curves were found to be similar in the TCCA leaching systems while differing from the oxidation curve of sulfur during the leaching processes. 

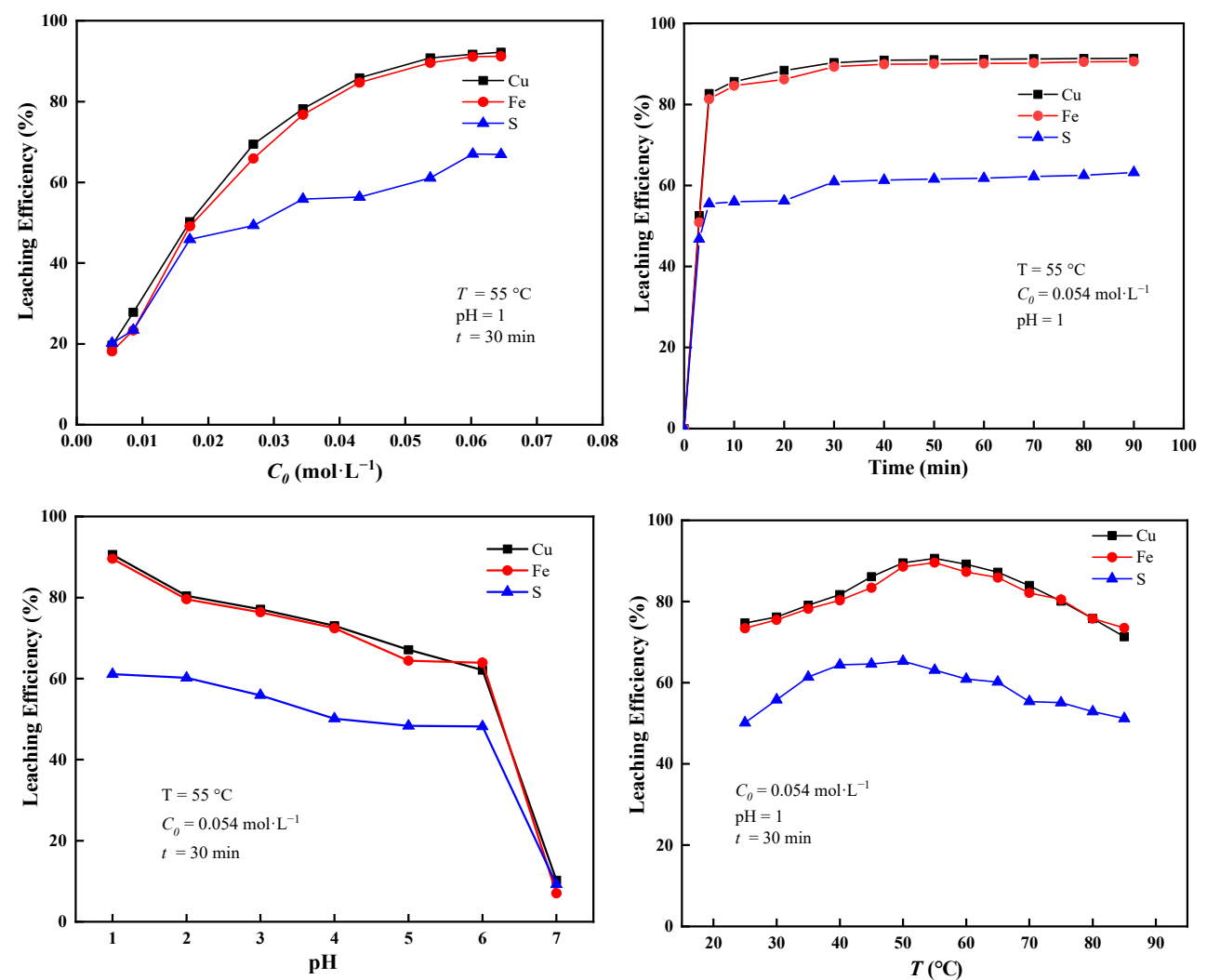

Figure 2. Extraction curves with TCCA.

It is also shown that the leaching efficiency of chalcopyrite increases significantly from $19.68 \%$ to $78.21 \%$, when the concentration of oxidant increases from 0.0054 to $0.034 \mathrm{~mol} \cdot \mathrm{L}^{-1}$. The experimental results confirm the fact that TCCA was the oxidant that strongly reacted with chalcopyrite. It can also be noted that after the amount of oxidant concentration exceeded $0.034 \mathrm{~mol} \cdot \mathrm{L}^{-1}$, the increase in Cu extraction became slow. Extractions of $90.8 \%$ $\mathrm{Cu}, 89.6 \% \mathrm{Fe}$ and $61.1 \% \mathrm{~S}$ were achieved when chalcopyrite was dissolved and when the TCCA concentration was $0.054 \mathrm{~mol} \cdot \mathrm{L}^{-1}$. The extreme use of TCCA with the aim of increasing the leaching efficiency of chalcopyrite does not seem reasonable.

It is easy to learn that the chalcopyrite dissolves rapidly using TCCA as an oxidant. The copper extraction obtained $82.64 \%$ when the reaction time was only $5 \mathrm{~min}(\mathrm{~min})$. When the reaction time is continuously increased to $30 \mathrm{~min}$, the leaching efficiency of chalcopyrite can reach $90.8 \%$. It is also apparently observed that after $30 \mathrm{~min}$, the copper, iron and sulfur extractions begin to stabilize. The leaching efficiency of $\mathrm{Cu}$ increased from $90.8 \%$ to $91.35 \%$ after prolonging the reaction time from 30 to $90 \mathrm{~min}$. The results show that the leaching speed of chalcopyrite with TCCA is quite fast at atmospheric conditions. The oxidation reaction can mostly complete in less than half an hour, suggesting that TCCA is a highly efficient leaching reagent for chalcopyrite. The result is better than the other oxidants, such as $\mathrm{FeCl}_{3}$, in previous reports [1,4].

It is also interesting to learn that $\mathrm{Cu}, \mathrm{Fe}$ and $\mathrm{S}$ extractions decrease steadily with the $\mathrm{pH}$ value increases. The percentage of leached copper was $62.11 \%$ when the $\mathrm{pH}$ value was controlled at 6 , about $28 \%$ less than that $\mathrm{pH}$ at 1 . The reason may be that at lower $\mathrm{pH}$ values, the hydrolysis of TCCA becomes easier with water. Thus, more products of hypochlorous acid and cyanuric acid can be generated and cause the chalcopyrite to leach faster. This can be proved by the fact that the oxidizing ability of TCCA fell sharply when the $\mathrm{pH}$ value was at 7 , and only about $10 \%$ copper was extracted from chalcopyrite in $30 \mathrm{~min}$. Therefore, the $\mathrm{pH}$ value is also one of the crucial influence factors.

It is noted that the amount of dissolved chalcopyrite first rises and then decreases in the temperature range of 25 and $85^{\circ} \mathrm{C}$. The maximum leaching efficiency of chalcopyrite 
was obtained when the reaction temperature was at $55^{\circ} \mathrm{C}$. On the positive side, the rising temperature can enhance the reaction rate and promote the diffusion of ions. However, the TCCA may decompose at high temperatures, resulting in a decrease in its oxidizing ability. The maximum difference of $\mathrm{Cu}$ and Fe extraction in the whole temperature range is nearly $20 \%$, showing that the role of the temperature is one of the key factors.

\subsection{Comparison with Other Common Reagents}

To compare with the other traditional methods, various reagents $\mathrm{NaClO}, \mathrm{NaClO}_{3}$, $\mathrm{FeCl}_{3}$ and $\mathrm{H}_{2} \mathrm{SO}_{4}$ were also applied to leach chalcopyrite at the same temperature of $55^{\circ} \mathrm{C}$ and reaction time of $30 \mathrm{~min}$. The dosage selections of the various reagents are controlled at $0.5 \mathrm{~mol} \cdot \mathrm{L}^{-1}$. The copper extraction results are shown in Figure 3. It is obvious that TCCA obtained relative advantages over the traditional reagents, though the reaction conditions may not be optimal for the other reagents.

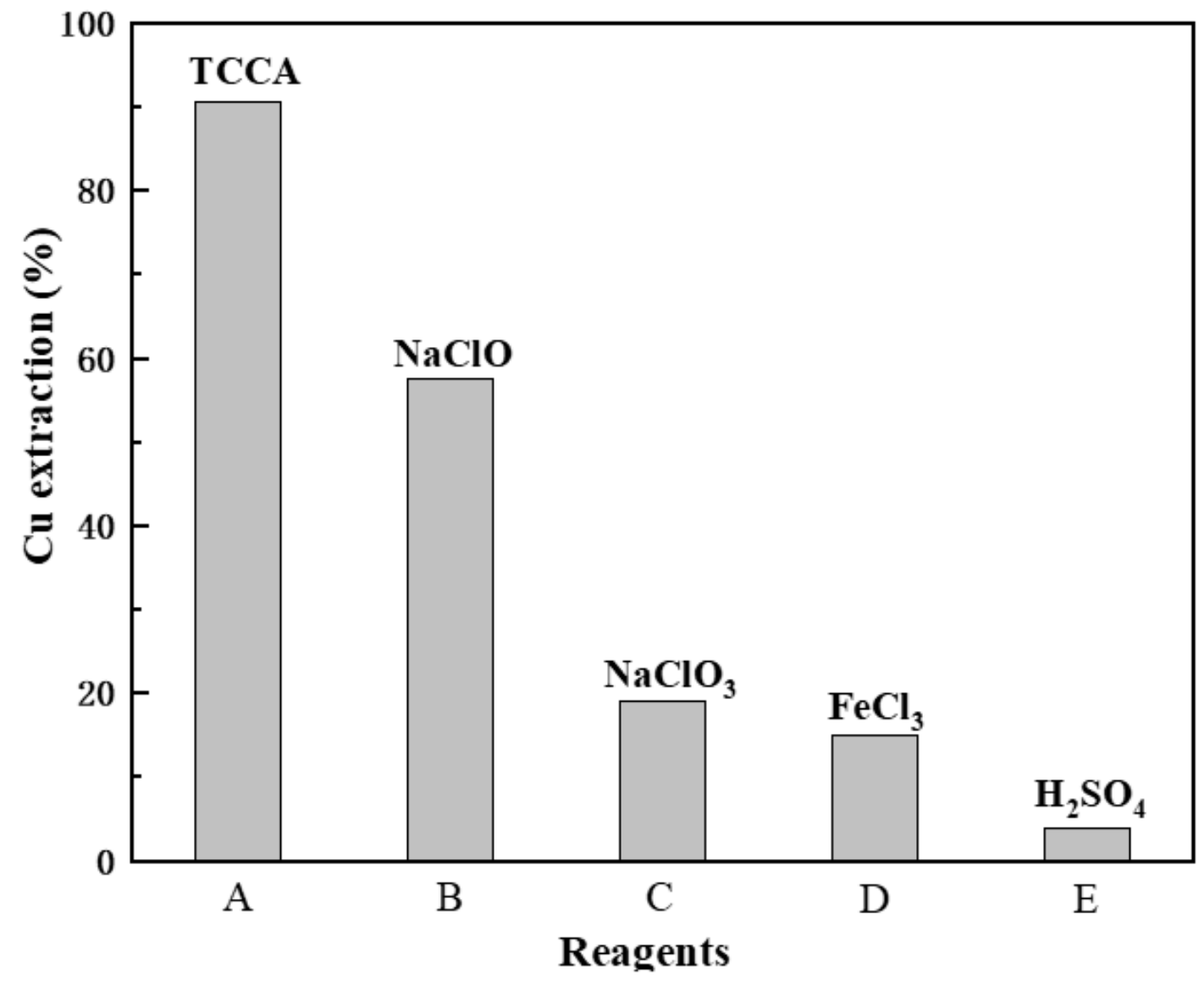

Figure 3. The comparison of copper extraction with different reagents: (A) $0.054 \mathrm{~mol} \cdot \mathrm{L}^{-1} \mathrm{TCCA}$; (B) $0.50 \mathrm{~mol} \cdot \mathrm{L}^{-1} \mathrm{NaClO}$; (C) $0.50 \mathrm{~mol} \cdot \mathrm{L}^{-1} \mathrm{NaClO}_{3}$; (D) $0.50 \mathrm{~mol} \cdot \mathrm{L}^{-1} \mathrm{FeCl}_{3}$ and $0.5 \mathrm{~mol} \cdot \mathrm{L}^{-1} \mathrm{HCl}$; (E) $0.50 \mathrm{~mol} \cdot \mathrm{L}^{-1} \mathrm{H}_{2} \mathrm{SO}_{4}$ at the same temperature $\left(55^{\circ} \mathrm{C}\right)$ and reaction time $(30 \mathrm{~min})$.

\subsection{Comparison with Pyrite Leaching}

As pyrite is a common sulfide mineral in the chalcopyrite ore, the comparison of leaching efficiency for the pure chalcopyrite and pure pyrite (Fe $45.32 \%$ and S 52.95\%) samples, obtained from the same mine located in the Yunnan Province of China, using TCCA reagent under the same reaction conditions was also studied, and the experimental results are shown in Figure 4. It was found that the pure pyrite can also be oxidized and dissolved by TCCA rapidly, which proves that the TCCA is an excellent leaching agent for the sulfide mineral. Since there is still a lot of refractory sulfide minerals that require new 
leaching methods, it is a promising leaching reagent which can be applied to those sulfide minerals.

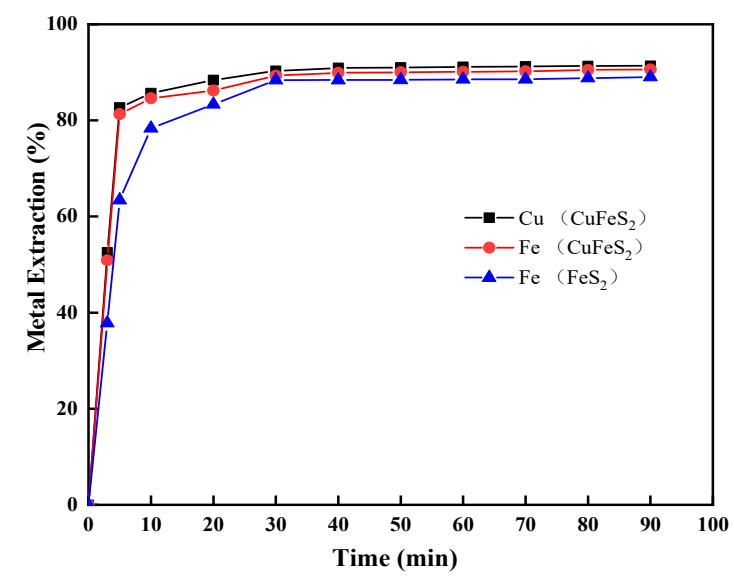

Figure 4. The comparison of leaching efficiency for chalcopyrite and pyrite using TCCA reagent under the same reaction conditions.

\subsection{Changes of Chalcopyrite before and after Leaching}

Leached residues collected after $30 \mathrm{~min}$ leaching in the $0.054 \mathrm{~mol} \cdot \mathrm{L}^{-1} \mathrm{TCCA}, \mathrm{pH} 1$ at $55{ }^{\circ} \mathrm{C}$ were characterized for X-ray Diffraction (XRD) analyses and scanning electron microscope (SEM). Figure 5 shows the XRD result of the leach residue specimen. The pattern was compared with the obtained pattern of untreated chalcopyrite concentrate shown in Figure 1. For the raw ore, it is concluded that chalcopyrite $\left(\mathrm{CuFeS}_{2}\right)$ with the JCPDS card numbers of 01-075-0253 are the major minerals. The intensity of the chalcopyrite peaks reduced in the leach residue and at the same time a new peak corresponding to the byproduct sulfur (JCPDS 00-008-0247) appeared. Although above $90 \%$ of chalcopyrite was leached by the strong oxidant TCCA and entered the oxidizing liquid mainly in an ionic state, the concentration of TCCA on the parts of the mineral surface may reduce during the late oxidation stage, and the descending oxidation capacity will be the main reason of the formation of elemental sulfur. Furthermore, the formed elemental sulfur can hinder the leaching process of chalcopyrite and weaken the TCCA further oxidation. It is consistent with reports using other leaching reagents, that is, moderate oxidizing conditions for chalcopyrite forms an elemental sulfur byproduct, while intense oxidizing conditions converts the sulfide into the sulfate directly [2].

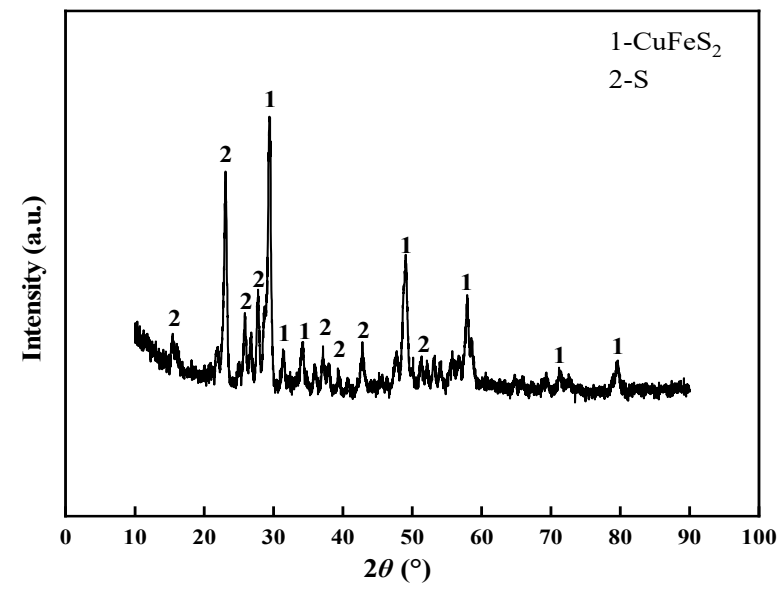

Figure 5. XRD pattern of leached residue.

SEM images of chalcopyrite before and after leaching experiments are given in Figure 6. It seems that most of the sample particles with relative uniform grain size of 
about $0.3 \mu \mathrm{m}$ adhere to each other before leaching (Figure 6a,b). After $30 \mathrm{~min}$ of leaching, there existed significant cavitation on the surface of the particles. The size of the cavity is even larger than $3 \mu \mathrm{m}$, as shown in Figure 6c. The smaller chalcopyrite cores of leach residue can be found in Figure $6 \mathrm{~d}$, and their shapes and sizes differ from one another. Elemental sulphur and other possible precipitations were hardly observed on the surface of the residue particles, which is different from other oxidants [1].
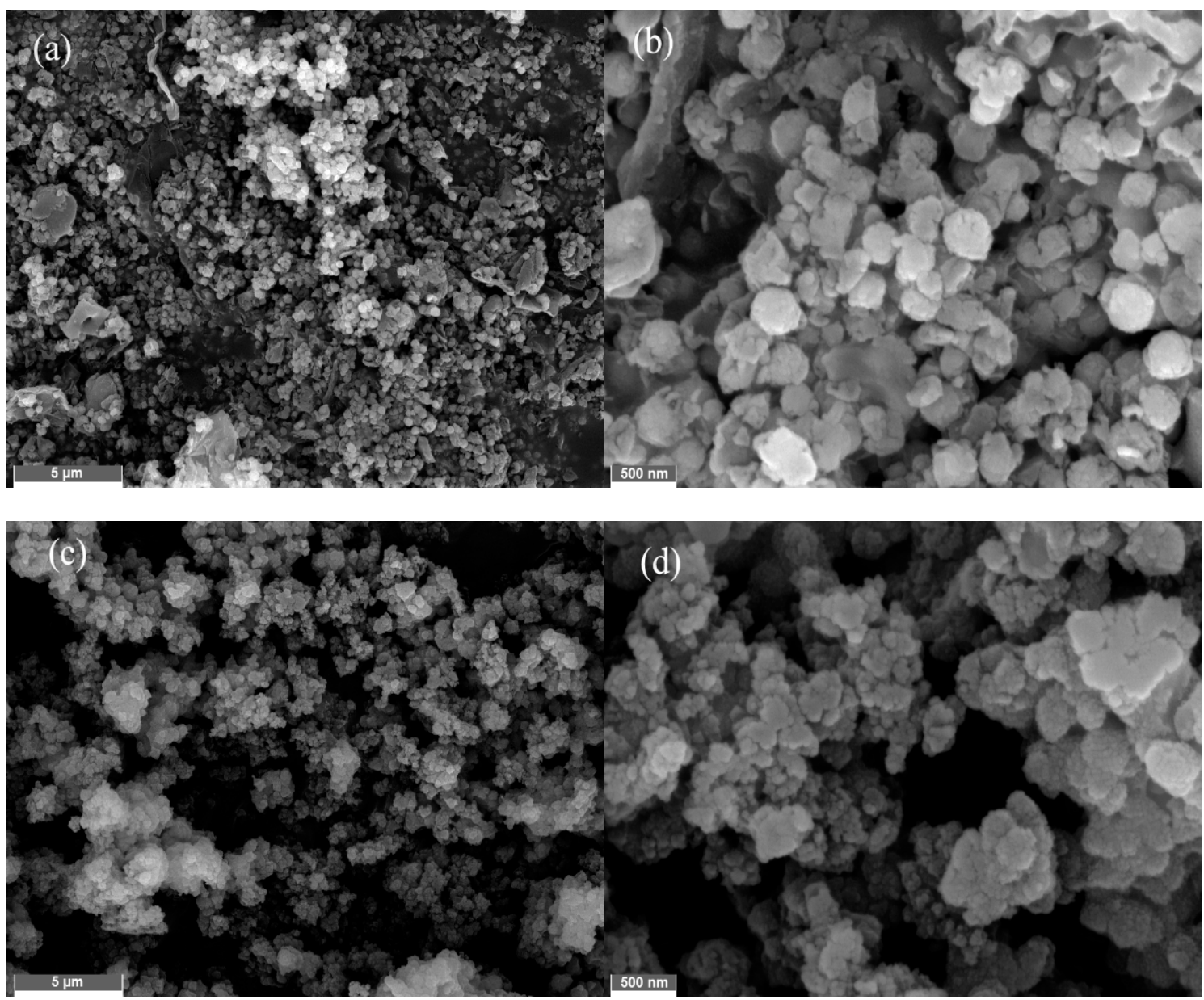

Figure 6. Morphologies of chalcopyrite specimens before leaching (a,b) and after chemical oxidation (c,d) as determined by SEM.

XPS analyses were conducted in order to figure out the evolution of the surface species on the chalcopyrite samples. High resolution XPS spectra of $\mathrm{Cu} 2 \mathrm{p}, \mathrm{Fe} 2 \mathrm{p}$ and S 2p of the two chalcopyrite specimens were obtained and are presented in Figure 7 . The $\mathrm{Cu} 2 \mathrm{p}$ spectrum of the unleached chalcopyrite in Figure 7a shows two strong peaks at 2p3/2 (932.3 and $931.2 \mathrm{eV})$ and one peak at 2p1/2 (951.2 eV). The $2 \mathrm{p} 3 / 2$ peak at $932.3 \mathrm{eV}$ indicates the presence of $\mathrm{Cu}(\mathrm{I})-\mathrm{S}$ [21]. The peaks of chalcopyrite after leaching are presented in Figure $7 \mathrm{~b}$. The peak at $2 \mathrm{p}_{1 / 2}$ was moved to $954.1 \mathrm{eV}$. It is apparent to find that the peak at $2 \mathrm{p}_{3 / 2}$ $(932.3 \mathrm{eV})$ was changed by the two strong peaks at 935.1 and $945.3 \mathrm{eV}$. The peak in the $\mathrm{Cu}$ $2 \mathrm{p}$ spectrum at $935.1 \mathrm{eV}$ could be assigned to the $\mathrm{Cu}(\mathrm{II})-\mathrm{O}$ species, such as $\mathrm{CuO}, \mathrm{Cu}(\mathrm{OH})_{2}$ and $\mathrm{Cu}_{3}\left(\mathrm{SO}_{4}\right)(\mathrm{OH})_{4}$, suggesting that the oxidation conditions of chalcopyrite are very extensive [20]. The peak at $2 \mathrm{p}_{3 / 2}(945.3 \mathrm{eV})$, the shake-up satellites in the spectra, confirmed that characteristic of the $\mathrm{Cu}$ (II) species of leached chalcopyrite after the TCCA oxidation.

XPS has also been used to determine the changes in oxidation state of Fe for chalcopyrite. As shown in Figure 7b, the peak at 707.2 and $710.8 \mathrm{eV}$ indicated the relevant compounds with the $2 \mathrm{p}_{3 / 2}$ binding energies of $\mathrm{Fe}^{2+}$ and $\mathrm{Fe}^{3+}$, respectively. The result is in agreement with the effective oxidation state of chalcopyrite being between $\mathrm{Cu}^{+} \mathrm{Fe}^{3+}\left(\mathrm{S}^{2-}\right)_{2}$ 
and $\mathrm{Cu}^{2+} \mathrm{Fe}^{2+}\left(\mathrm{S}^{2-}\right)_{2}$, which was caused by the significant covalent bonding [22]. After leaching, the peak at $707.2 \mathrm{eV}$ was found to disappear in the leach residue, which confirmed that $\mathrm{Fe}^{2+}$ was oxidized by TCCA and was no longer exited. The sharp peak at $711.9 \mathrm{eV}$ could be assigned to Fe (III)-SO species.
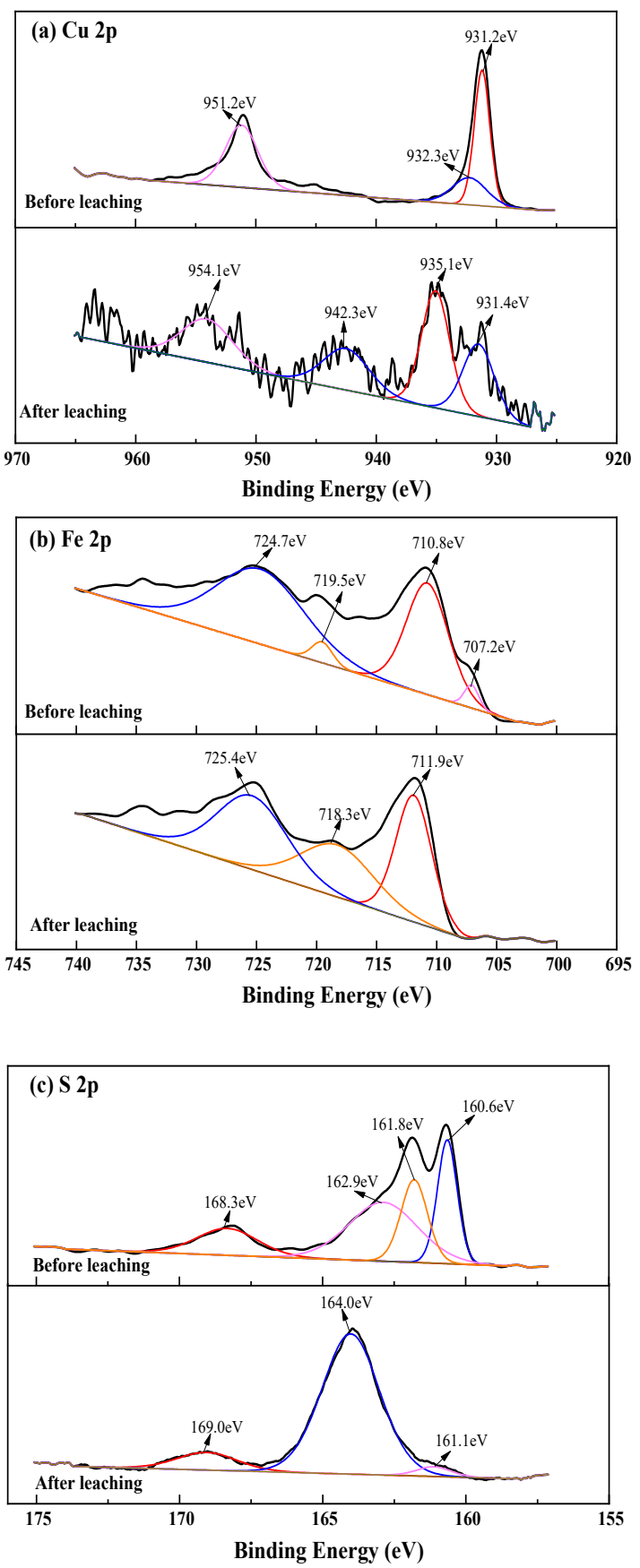

Figure 7. XPS spectra showing (a) Cu 2p, (b) Fe 2p and (c) S 2p peaks from the surface of specimens collected from unleached chalcopyrite and leached residue.

In the S $2 \mathrm{p}$ spectrum (Figure 7c), the XPS spectra of unleached chalcopyrite can be fitted to four peaks at the binding energies of 160.6, 161.8, 162.9 and $168.3 \mathrm{eV}$, which were identified to be the peaks of $\mathrm{S}^{2-}, \mathrm{S}_{2}{ }^{2-}, \mathrm{S}_{\mathrm{n}}{ }^{2-}$ and $\mathrm{SO}_{4}{ }^{2-}$, respectively, suggesting the existence of $\mathrm{Cu}(\mathrm{I})-\mathrm{S}$ [23]. The absence of peaks at 160.6 and at $162.9 \mathrm{eV}$ was detected for the leached residue, while the peak at $164.0 \mathrm{eV}$ assigned to $\mathrm{S}^{0}$ appeared in the $\mathrm{S} 2 \mathrm{p}$ spectrum. The results were consistent with the XRD patterns in Figure 5. The sulfur species in the leached residue exist in the form of elemental sulfur and chalcopyrite, and no other 
species were identified. Common passivation layers, such as copper-rich sulfide, disulfide $\left(\mathrm{S}_{2}{ }^{2-}\right)$, polysulfide $\left(\mathrm{S}_{\mathrm{n}}{ }^{2-}\right)$ and Fe hydroxy-oxide were not detected for the chalcopyrite leach residue.

\subsection{Changes of Chalcopyrite before and after Leaching}

The leaching process of chalcopyrite can be controlled by the surface chemical reaction (kinetic models Equations (1) and (2))or the diffusion reaction (kinetic models Equations (3) and (4)) through the product layer.

$$
\begin{gathered}
1-(1-x)^{1 / 3}=k t \\
-\ln (1-x)=k t \\
1+2(1-x)-3(1-x)^{2 / 3}=k t \\
{\left[1-(1-x)^{1 / 3}\right]^{2}=k t}
\end{gathered}
$$

In the formula, $x$ is the $\mathrm{Cu}$ extraction, $t$ means leaching time, and $k$ corresponds to the reaction kinetic constants. Figure 8 shows the plots and the fitting lines of kinetic models. Table 1 presented the kinetic constant $(k)$ and the regression coefficients $\left(R^{2}\right)$ calculated from the experimental dissolution results using the four possible kinetic equations. It is seen from Table 1 that average R2 changes little from the various models. This may be ascribed to the high leaching speed and that most of the product was soluble sulfate, which cannot form a passivation layer. Therefore, both the surface chemical reaction and the diffusion reaction are easy to carry on. The model Equation (4) was relatively more fitted to the copper dissolution data due to higher average $R^{2}$ values.
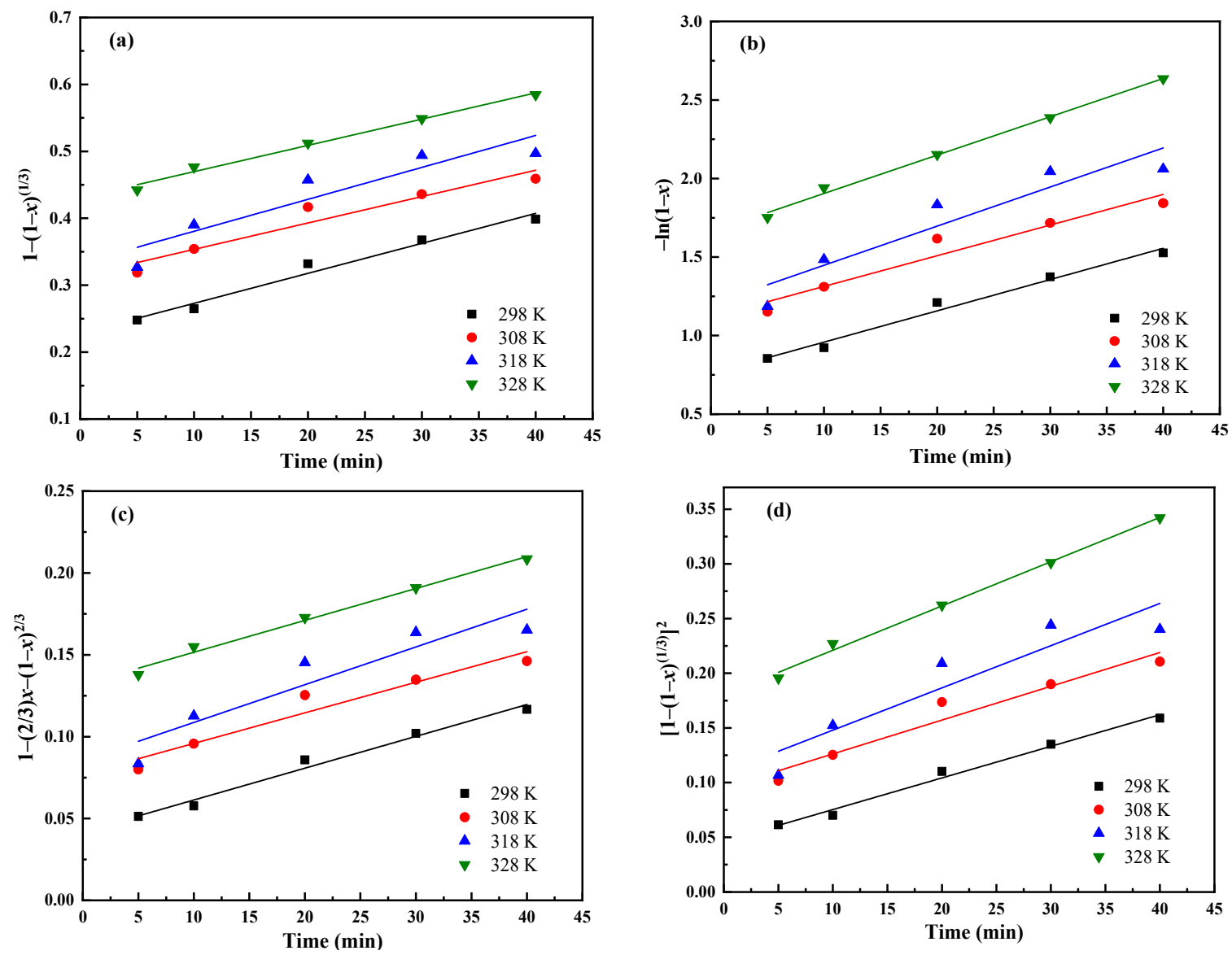

Figure 8. Plots of kinetic models: (a) $1-(1-x)^{1 / 3}$ vs. time; (b) $-\ln (1-x)$ vs. time; (c) $1-(2 / 3) x-(1-x)^{2 / 3}$ vs. time; (d) $\left[1-(1-x)^{1 / 3}\right]^{2}$ vs. time. 
Table 1. The rate constants, $k$ and the coefficients of variation, $R^{2}$ for each kinetics model.

\begin{tabular}{|c|c|c|c|c|c|}
\hline Rate-Controlled Steps & Models & $\begin{array}{c}\text { Temperatures } \\
\text { (K) }\end{array}$ & $\begin{array}{c}k \\
\left(\min ^{-1}\right)\end{array}$ & $R^{2}$ & $\begin{array}{c}R^{2} \\
\text { Average }\end{array}$ \\
\hline \multirow{8}{*}{ Surface chemical reaction } & \multirow{4}{*}{$1-(1-x)^{1 / 3}=k t$} & 298 & 0.00448 & 0.9777 & \multirow{4}{*}{0.9408} \\
\hline & & 308 & 0.00394 & 0.9293 & \\
\hline & & 318 & 0.00477 & 0.8664 & \\
\hline & & 328 & 0.00392 & 0.9899 & \\
\hline & \multirow{4}{*}{$-\ln (1-x)=k t$} & 298 & 0.01991 & 0.9841 & \multirow{4}{*}{0.9466} \\
\hline & & 308 & 0.01952 & 0.9224 & \\
\hline & & 318 & 0.02489 & 0.8849 & \\
\hline & & 328 & 0.02441 & 0.9951 & \\
\hline \multirow{8}{*}{$\begin{array}{l}\text { Diffusion through the } \\
\text { product layer }\end{array}$} & \multirow{4}{*}{$1-(2 / 3) x-(1-x)^{2 / 3}=k t$} & 298 & 0.00194 & 0.9841 & \multirow{4}{*}{0.9459} \\
\hline & & 308 & 0.00187 & 0.9360 & \\
\hline & & 318 & 0.00231 & 0.8739 & \\
\hline & & 328 & 0.00195 & 0.9898 & \\
\hline & \multirow{4}{*}[1-(1-x)^{1/3}]{$^{2}=k t$} & 298 & 0.00289 & 0.9842 & \multirow{4}{*}{0.9479} \\
\hline & & 308 & 0.00309 & 0.9479 & \\
\hline & & 318 & 0.00386 & 0.8644 & \\
\hline & & 328 & 0.00405 & 0.9951 & \\
\hline
\end{tabular}

\subsection{Discussion of Reaction Mechanism}

In general, the amount of leached copper entering into the solution increased with the extension of leaching time at certain temperatures. To further understand the temperature effects upon leaching rate, the Arrhenius equation (Equation (5) was applied to determine the activation energy of chalcopyrite leaching.

$$
k^{\prime}=A \mathrm{e}^{-E \mathrm{a} / R T}
$$

In the formula, $k^{\prime}$ corresponds to the reaction rate constant $\left(k^{\prime}=d C / d t, C\right.$ is the copper content, $t$ is reaction time); $A$ is the pre-exponential factor; $E_{\mathrm{a}}$ is the activation energy of the chalcopyrite dissolution process $\left(\mathrm{J} \cdot \mathrm{mol}^{-1}\right) ; T$ is the absolute temperature in Kelvin $(\mathrm{K})$ and $R$ is the universal gas constant $\left(\mathrm{J} \cdot \mathrm{mol}^{-1} \cdot \mathrm{K}^{-1}\right)$.

The fitting of the $\ln k^{\prime}$ against $1 / T 10^{-3}$ was shown in Figure 9 according to the data collected at the optimum conditions (TCCA concentration $0.054 \mathrm{~mol} \cdot \mathrm{L}^{-1}$ and $\mathrm{pH} 1$ ) with the different temperatures and reaction times. The calculated result of $E_{a}=9.06 \mathrm{~kJ} \cdot \mathrm{mol}^{-1}$ from the Arrhenius plots confirms that $\mathrm{CuFeS}_{2}$ leaching is very fast and prone to be controlled by a diffusion reaction. In addition, the activation energy is, up until now, the lowest one compared with that in other previous reports studying chalcopyrite leaching. According to the above measurement results, it can be considered that TCCA is an efficient lixiviant for chalcopyrite.

Leaching mechanisms for chalcopyrite with different lixiviants, such as sulfates, chlorides, ammonia and nitrates, have been proposed. At present, the leaching mechanism researches mainly focus on the product layer formed on the surface of chalcopyrite and the effects of these surface species on the leaching process [11,13]. Common surface products of chalcopyrite leaching are sulfur, sulfide and iron oxides.

In a sulfuric acid system, if ferric iron is used as the oxidant, most of S (94\%) can be converted to $\mathrm{S}^{0}$, and the remaining of $\mathrm{S}$ in $\mathrm{CuFeS}_{2}$ is oxidized to $\mathrm{SO}_{4}{ }^{2-}$ (Equation (6). For the dissolved oxygen as an oxidant, the product in the leaching of chalcopyrite is also mostly elemental sulfur (Equation (7)). The formed elemental sulfur on the chalcopyrite surface will hinder the reaction rate as a passivation coating, as shown in Figure 10. Therefore, only when the system potential is high or a strong oxidant such as hydrogen peroxide is applied (Equation (8)), the sulfur in chalcopyrite can then be oxidized to $\mathrm{SO}_{4}{ }^{2-}$ and enhance the Cu extraction.

$$
\mathrm{CuFeS}_{2}+4 \mathrm{Fe}^{3+} \rightarrow \mathrm{Cu}^{2+}+5 \mathrm{Fe}^{2+}+2 \mathrm{~S}^{0}
$$




$$
\begin{gathered}
\mathrm{CuFeS}_{2}+4 \mathrm{H}^{+}+\mathrm{O}_{2} \rightarrow \mathrm{Cu}^{2+}+\mathrm{Fe}^{2+}+2 \mathrm{~S}^{0}+2 \mathrm{H}_{2} \mathrm{O} \\
2 \mathrm{CuFeS}_{2}+17 \mathrm{H}_{2} \mathrm{O}_{2}+2 \mathrm{H}^{+} \rightarrow 2 \mathrm{Cu}^{2+}+2 \mathrm{Fe}^{3+}+\mathrm{SO}_{4}^{2-}+18 \mathrm{H}_{2} \mathrm{O}
\end{gathered}
$$

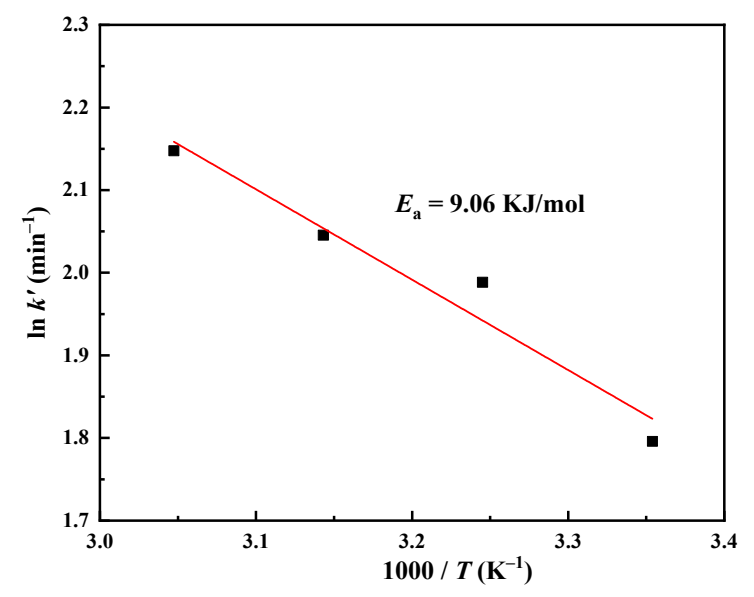

Figure 9. The relationship between $\ln k^{\prime}$ and 1000/T.

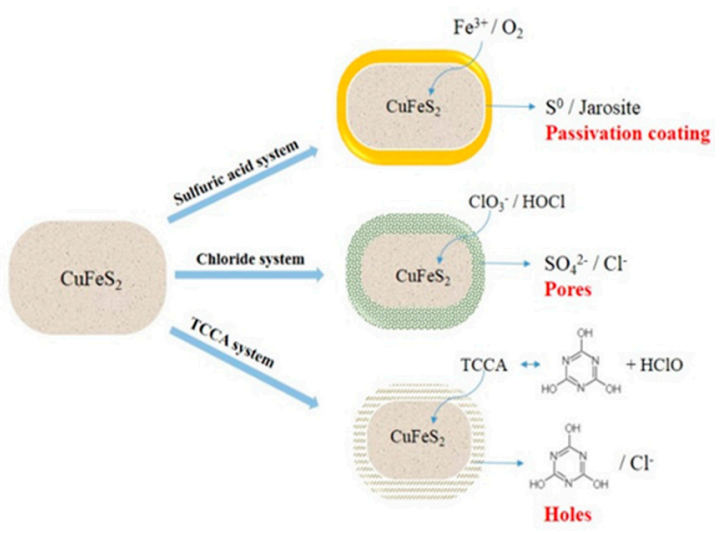

Figure 10. The proposed mechanisms of chalcopyrite leaching in different systems.

In a chloride system, chloride ions change the morphology of the deposited sulfur layer, and the product sulfur rarely associates with chalcopyrite particles and mainly appears in the form of isolated spherical pellets with higher crystallinity. In the absence of chloride, the leached chalcopyrite particles are completely covered by an amorphous or cryptocrystalline film of sulfur (Figure 10). Therefore, in the presence of chloride ions in the solution, the leaching of chalcopyrite is much easier. However, when there are enough chloride ions in the solution, the leaching kinetics becomes less affected by the concentration of chloride ions. The chloride concentration is greater than $0.5 \mathrm{M}$, and increasing the chloride ion has little effect on the leaching rate of chalcopyrite [11]. When strong oxidants, such as chlorate and hypochlorous acid, etc., are added to the chloride system, most of the sulfur in chalcopyrite can be directly oxidized to $\mathrm{SO}_{4}{ }^{2-}$ (Equations (9) and (10)), and the oxidizing property of hypochlorous acid is higher than that of chlorate [7].

$$
\begin{aligned}
& 6 \mathrm{CuFeS}_{2}+17 \mathrm{ClO}^{3-}+6 \mathrm{H}^{+} \rightarrow 6 \mathrm{Cu}^{2+}+6 \mathrm{Fe}^{3+}+12 \mathrm{SO}_{4}{ }^{2-}+17 \mathrm{Cl}^{-}+3 \mathrm{H}_{2} \mathrm{O} \\
& 2 \mathrm{CuFeS}_{2}+17 \mathrm{HOCl}+2 \mathrm{H}_{2} \mathrm{O} \rightarrow 2 \mathrm{Cu}^{2+}+\mathrm{Fe}_{2} \mathrm{O}_{3}+4 \mathrm{SO}_{4}{ }^{2-}+17 \mathrm{Cl}^{-}+21 \mathrm{H}^{+}
\end{aligned}
$$

In the novel TCCA leaching system, TCCA firstly undergoes a dissolution reaction in the solution to generate cyanuric acid and strong oxidizing hypochlorous acid. The reaction equation is as follows:

$$
\mathrm{C}_{3} \mathrm{~N}_{3} \mathrm{O}_{3} \mathrm{Cl}_{3}+3 \mathrm{H}_{2} \mathrm{O} \rightleftarrows \mathrm{C}_{3} \mathrm{~N}_{3} \mathrm{O}_{3} \mathrm{H}_{3}+3 \mathrm{HClO}
$$


The formed hypochlorous acid is the main oxidant for oxidative leaching of chalcopyrite. However, pure hypochlorous acid is considered to be in a weak acid environment such as $\mathrm{pH} 4-5$, while for TCCA, it is more beneficial to chalcopyrite leaching as the acidity is lower. One of the reasons is that low acidity can promote its dissolution and hydrolysis equilibrium reaction. Secondly, it is obvious that the presence of cyanuric acid has an important influence on the extraction of chalcopyrite. The possible reasons for its effect are proposed as follows: (1) cyanuric acid is a stabilizer of hypochlorous acid, which can reduce hypochlorous acid decomposition consumption, which maintains its sufficient reaction concentration; (2) similarly to chloride ions, cyanuric acid is not only a complexing reagent for metal ions but also prevents the agglomeration and accumulation of product sulfur, and because of its large size, it can achieve better effects than chloride ions. Furthermore, the reaction chalcopyrite and TCCA-generated hypochlorous acid can also produce a large amount of $\mathrm{Cl}-$, making it in the chloride system and promoting the chalcopyrite leaching. From the above results, using TCCA as a reagent for chalcopyrite leaching, a low activation energy and high reaction rate will be obtained.

\section{Conclusions}

A common and cheap TCCA was applied to increase $\mathrm{CuFeS}_{2}$ leaching efficiency and copper recovery in the leaching solution. Cu extraction grows significantly with the increase in reaction time and the TCCA concentration, whereas it falls with the rise of $\mathrm{pH}$ value. The oxidation speed is confirmed to be very high using TCCA. Extractions of $90.8 \% \mathrm{Cu}$, $89.6 \% \mathrm{Fe}$ and $61.1 \% \mathrm{~S}$ were obtained in the following leaching conditions: the oxidant concentration is $0.054 \mathrm{~mol} \cdot \mathrm{L}^{-1}$, the temperature is $55^{\circ} \mathrm{C}$, the $\mathrm{pH}$ is 1 and the reaction time is $30 \mathrm{~min}$. It is concluded that the composition of leached residue is elemental sulfur and unreacted chalcopyrite. Common passivation layers, such as copper-rich sulfide, disulfide $\left(\mathrm{S}_{2}{ }^{2-}\right)$, polysulfide $\left(\mathrm{S}_{\mathrm{n}}{ }^{2-}\right)$ and Fe hydroxy-oxide were not detected for the chalcopyrite leach residue. The surface reaction and diffusion process present no obvious difference, and the activation energy of the whole leaching reaction is calculated as $9.06 \mathrm{~kJ} \cdot \mathrm{mol}^{-1}$. The leaching mechanism infers that the products TCCA hydrolyzed, hypochlorous acid and cyanuric acid, resulted in the rapid leaching of chalcopyrite. TCCA is expected to be applied in hydrometallurgical leaching processes in the future.

Author Contributions: Conceptualization, G.C.; methodology, G.C.; validation, J.S. and H.Y.; formal analysis, J.S.; investigation, S.G.; resources, P.M.; data curation, J.S.; writing - original draft preparation, G.C.; writing - review and editing, G.C.; project administration, G.C.; funding acquisition, G.C. All authors have read and agreed to the published version of the manuscript.

Funding: This research and the APC was funded by the National Key R\&D Program of China (2018YFC1902003), the Fundamental Research Funds for the Central Universities (N172504022).

Acknowledgments: This research was supported by Northeastern University Testing Center. The authors would also like to acknowledge Linlin Tong, Youjing, Fan, and Zhenan Jin for technical and laboratory assistance.

Conflicts of Interest: The authors declare no conflict of interest.

\section{References}

1. Li, Y.; Kawashima, N.; Li, J.; Chandra, A.P.; Gerson, A.R. A review of the structure, and fundamental mechanisms and kinetics of the leaching of chalcopyrite. Adv. Colloid Interf. Sci. 2013, 197-198, 1-32. [CrossRef] [PubMed]

2. Ghomi, M.A.; Mozammel, M.; Moghanni, H.; Shahkar, L. Atmospheric leaching of chalcopyrite in the presence of some polar organic reagents: A comparative study and optimization. Hydrometallurgy 2019, 189, 105120. [CrossRef]

3. Klauber, C. A critical review of the surface chemistry of acidic ferric sulphate dissolution of chalcopyrite with regards to hindered dissolution. Int. J. Miner. Process. 2008, 86, 1-17. [CrossRef]

4. Watling, H.R. Chalcopyrite hydrometallurgy at atmospheric pressure: 2. Review of acidic chloride process options. Hydrometallurgy 2014, 146, 96-110. [CrossRef]

5. Moyo, T.; Petersen, J.; Nicol, M.J. The electrochemistry and kinetics of the oxidative dissolution of chalcopyrite in ammoniacal solutions. Part II-Cathodic reactions. Hydrometallurgy 2019, 184, 67-74. [CrossRef] 
6. Sokić, M.D.; Marković, B.R.; Živković, D. Kinetics of chalcopyrite leaching by sodium nitrate in sulphuric acid. Hydrometallurgy 2009, 95, 273-279. [CrossRef]

7. Shiers, D.W.; Collinson, D.M.; Kelly, N.J. Copper extraction from chalcopyrite: Comparison of three non-sulfate oxidants, hypochlorous acid, sodium chlorate and potassium nitrate, with ferric sulfate. Miner. Eng. 2016, 85, 55-65. [CrossRef]

8. Ahn, J.; Wu, J.; Lee, J. Investigation on chalcopyrite leaching with methanesulfonic acid (MSA) and hydrogen peroxide. Hydrometallurgy 2019, 187, 54-62. [CrossRef]

9. Mehmet, D.T. Optimization of selective copper extraction from chalcopyrite concentrate in presence of ammonium persulfate and ammonium hydroxide. Int. J. Miner. Metall. Mater. 2019, 26, 946-952.

10. Nikkhou, F.; Xia, F.; Deditius, A.P. Variable surface passivation during direct leaching of sphalerite by ferric sulfate, ferric chloride, and ferric nitrate in a citrate medium. Hydrometallurgy 2019, 188, 201-215. [CrossRef]

11. Kartal, M.; Xia, F.; Ralph, D.; Rickard, W.D.A.; Renard, F.; Li, W. Enhancing chalcopyrite leaching by tetrachloroethylene-assisted removal of sulphur passivation and the mechanism of jarosite formation. Hydrometallurgy 2020, 19, 105192. [CrossRef]

12. Dreisinger, D.; Abed, N. A fundamental study of the reductive leaching of chalcopyrite using metallic iron part I: Kinetic analysis. Hydrometallurgy 2002, 66, 37-57. [CrossRef]

13. Granata, G.; Takahashi, K.; Kato, T.; Tokoro, C. Mechanochemical activation of chalcopyrite: Relationship between activation mechanism and leaching enhancement. Miner. Eng. 2019, 131, 280-285. [CrossRef]

14. Wen, T.; Zhao, Y.; Ma, Q.; Xiao, Q.; Zhang, T.; Chen, J.; Song, S. Microwave improving copper extraction from chalcopyrite through modifying the surface structure. J. Mater. Res. Technol. 2020, 9, 263-270. [CrossRef]

15. Yoon, H.; Kim, C.; Chung, K.W. Ultrasonic-assisted leaching kinetics in aqueous $\mathrm{FeCl}_{3}-\mathrm{HCl}$ solution for the recovery of copper by hydrometallurgy from poorly soluble chalcopyrite. Korean J. Chem. Eng. 2017, 34, 1748-1755. [CrossRef]

16. Ikiz, D.; Gülfen, M.; Aydin, A.S. Dissolution kinetics of primary chalcopyrite ore in hypochlorite solution. Miner. Eng. 2006, 19, 972-974. [CrossRef]

17. Choubey, P.K.; Lee, J.-C.; Kim, M.-S.; Kim, H.-S. Conversion of chalcopyrite to copper oxide in hypochlorite solution for selective leaching of copper in dilute sulfuric acid solution. Hydrometallurgy 2018, 178, 224-230. [CrossRef]

18. Gaspa, S.; Carraro, M.; Pisano, L. Trichloroisocyanuric Acid: A Versatile and Efficient Chlorinating and Oxidizing Reagent. Eur. J. Org. Chem. 2019, 22, 3544-3552. [CrossRef]

19. Wengert, M.; Sanseverino, A.M.; De Mattos, M.C.S. Trichloroisocyanuric acid: An alternate green route for the transformation of alkenes into epoxides. J. Braz. Chem. Soc. 2002, 13, 700-703. [CrossRef]

20. Tilstam, U.; Weinmann, H. Trichloroisocyanuric acid: A safe and efficient oxidant. Org. Process Res. Dev. 2002, 6, 384-393. [CrossRef]

21. Wang, J.; Gan, X.; Zhao, H.; Hu, M.; Li, K.; Qin, W.; Qiu, G. Dissolution and passivation mechanisms of chalcopyrite during bioleaching: DFT calculation, XPS and electrochemistry analysis. Miner. Eng. 2016, 98, 264-278. [CrossRef]

22. Hall, S.R.; Stewart, J.M. The crystal structure refinement of chalcopyrite, CuFeS 2 . Acta Crystallogr. B 1973, 29, 579-585. [CrossRef]

23. Li, Y.Y.; Liang, J.L.; He, X.; Zhang, L.; Liu, Y. Kinetics and mechanisms of amorphous FeS $_{2}$ induced Cr (VI) reduction. J. Hazard. Mater. 2016, 320, 216-225. [CrossRef] [PubMed] 